Strazicich, M.C. (2002). International Evidence of Tax Smoothing in a Panel of Industrial Countries. Applied Economics, 34(18): 2325-2331 (Dec 2002). Published by Taylor \& Francis (ISSN: 0003-6846). DOI: $10.1080 / 00036840210143107$.

\title{
International evidence of tax smoothing in a panel of industrial countries
}

Mark C. Strazicich

\begin{abstract}
A panel of industrial countries is examined for evidence of 'tax smoothing'. Tax smoothing results when governments minimize tax distortions over time. The model provides a positive theory of government debt and is due primarily to Barro. Unit root tests are performed in panel data to test the null hypothesis of nonstationary tax rates. Panel regressions are then undertaken to test the null hypothesis that tax rate changes are unpredictable and test for evidence of an alternative hypothesis. Political and economic variables are examined for their ability to predict tax rate changes. Overall, the results cannot reject the null hypotheses and support tax smoothing by national governments.
\end{abstract}




\section{INTRODUCTION}

The goal of this paper is to contribute towards understanding the behaviour of government debt. Tax smoothing results when governments 'smooth' tax rates to minimize the costs of taxation over time. If the marginal costs of taxation are an increasing function of the amount of resources taxed, given a long-run balanced budget constraint, then minimization of the total costs of taxation implies that the planned tax rate will be constant over time. Changes in the tax rate will be unpredictable and the tax rate will behave as a random walk. Temporary deviations in government spending and output from their permanent levels will result in a deficit or surplus, but no change in the tax rate. The model provides a positive theory of government debt and is due primarily to Barro (1979).

This study examines two implications of the tax smoothing model. First, the random walk implication predicts that the tax rate will be a nonstationary time series with a unit root. Second, tax smoothing implies that tax rate changes will be unpredictable. Therefore, lagged information should not be useful in predicting tax rate changes. These implications are examined by testing the null hypotheses that the tax rate has a unit root and that tax rate changes are orthogonal to lagged information. To address some recent criticisms that political factors might prevent tax smoothing, political variables are included in the lagged information set. Significant lagged information could also provide evidence of an alternative hypothesis. Testing is undertaken in panels created by pooling time series from 19 industrial countries. The use of panel data significantly increases the power of the tests to reject their null hypotheses. Annual central government data is examined for the period $1955 \pm 1988$. Overall, the results cannot reject the null hypotheses and support tax smoothing by national governments.

Section II discusses the theory of tax smoothing and reviews some of the literature. Section III describes the model. Section IV discusses the data. Section V presents the empirical results. Section VI summarizes and concludes.

\section{BACKGROUND}

Tax smoothing implies that governments set tax rates so as to minimize the cost of intertemporal tax distortions. Given the information available today, the tax rate would be considered 
as permanent and would be changed only with new information about future government spending and output. No prediction could be made of tax rate changes and the tax rate would behave as a random walk.

Empirical testing of the tax smoothing theory has focused on single country tests. See, for example, Barro (1981, 1986), Sahasakul (1986), Kochin et al. (1986), Trehan and Walsh (1988), Bizer and Durlauf (1990, 1991), Gupta (1992), Huang and Lin (1993) and Strazicich (1997). Results of these tests have been mixed. Barro, Kochin et al., Huang and Lin, and Strazicich find general support for tax smoothing when examining US federal tax rates. Gupta finds evidence of tax smoothing when examining Canadian federal tax rates. Contrary to this, Sahasakul and Bizer and Durlauf reject tax smoothing when examining US federal tax rates. Trehan and Walsh reject tax smoothing when examining US federal tax revenues. These tests examine either the time series properties of the data or test regression models derived from tax smoothing.

One exception to performing single country tests is Roubini and Sachs (1989). Using a reduced form model of the deficit derived from tax smoothing; Roubini and Sachs test a panel of 14 OECD countries for evidence of tax smoothing. General government deficits are regressed on a number of variables suggested by tax smoothing. They include a measure of political influence that, if significant, may be unfavourable to tax smoothing. Roubini and Sachs find budget deficits to be significantly affected by political factors, especially since 1975, and reject tax smoothing. They suggest that political factors, in particular the cohesion of national governments, significantly affect the budget making process to the detriment of tax smoothing. For example, a weakly cohesive government might ignore such forward looking costs as intertemporal tax distortions. In separate single country tests they regress the first differenced tax rate on a constant term. They reject tax smoothing after finding a significant constant term, or 'drift', for most countries.

A number of issues can be raised regarding the testing methodology employed by Roubini and Sachs. One potential problem with their methodology is its reliance on correctly specifying a particular reduced-form model. If the model tested is not correctly specified, then biased estimates may result. The authors describe a model where the budget deficit is a function of last year's deficit, the change in unemployment, the change in output growth, the change in the rate of real interest minus the rate of 
growth of output multiplied by the lagged debt-to-GDP ratio, and a political cohesion variable. Tax smoothing hypothesizes that temporary changes in government spending will be financed by changes in the government's budget balance but with no change in the tax rate. Roubini and Sachs use changes in unemployment and GDP growth to account for temporary changes in the ratio of government spending to GDP. While correct in principle, a more direct measure of temporary government spending to output is not included. As such, their results may be sensitive to their measure of temporary government spending to output. Bias regression coeficients will result if changes in unemployment and GDP growth do not accurately measure the ratio of temporary government spending to output. The model tested by Sahasakul is subject to this same potential criticism. Contrary to this, the methodology employed in this paper does not depend on accurately specifying a particular reduced-form model.

A second potential problem with the approach in Roubini and Sachs relates to their use of general government data. Benjamin and Kochin $(1978,1982)$ suggest that resource mobility may constrain state and local governments from smoothing tax rates. As deficits and surpluses occur, mobile resources would be encouraged to seek out taxable jurisdictions where current government spending exceeds current taxes and vice versa. Therefore, the ability of state and local governments to smooth tax rates would be diminished. Resource mobility predicts that state and local governments will balance budgets and not smooth tax rates. Strazicich $(1996,1997)$ presents evidence from the USA and Canada in support of this argument. Thus, inclusion of revenue from all levels of government in the tax rate measure tested by Roubini and Sachs could bias results in favour of rejecting tax smoothing.

The final issue deals with the assumption by Roubini and Sachs that a drift in tax rates rejects tax smoothing. If the marginal cost function of the tax rate was decreasing over time, tax smoothing would predict an upward drift in the tax rate. Therefore, finding a significant drift in tax rates is not sufficient to reject tax smoothing. 1

\section{III . THE MODEL}

The tax smoothing model, in panel data, assumes a government budget identity for country $i$ at period $t$ as follows:

$$
G_{i t}+r_{i t} B_{i t}-1 \equiv T_{i t}+\left(B_{i t}-B_{i t-1}\right)
$$


where $G_{i t}$ is real total government expenditures excluding interest on the national debt, $B_{i t}$ is the real stock of national debt outstanding at the end of period $t, T_{i t}$ is real tax revenue, and $r_{i t}$ is the real rate of interest. Dividing terms in Equation 1 by $Y_{\text {it }}$ (real output of country $i$ ), an intertemporal budget constraint can be expressed as follows:

$$
\begin{aligned}
g_{i t}+\sum_{k=1}^{\infty} E\left(g_{i t+k}\left(1+\rho_{i}\right)^{-k}\right) & +\left(1+\rho_{i}\right) b_{i t-1} \\
= & \tau_{i t}+\sum_{k=1}^{\infty} E\left(\tau_{i t+k}\left(1+\rho_{i}\right)^{-k}\right)
\end{aligned}
$$

where $E$ is the expectation operator, $G_{i t} \equiv / Y_{i t}, \tau_{i t} \equiv$ $T_{i t} / Y_{i t}, b_{i t} \equiv B_{i t} / Y_{i t}$ and $\rho_{i}$ is the real rate of interest minus the rate of growth of real output for country $i$ and is assumed to be time invariant.

The costs of taxation are assumed to increase quadratically with the 'tax rate' $\left(\tau_{i t}\right)$, implying that the marginal cost of tax collection is an increasing function of $\tau_{\text {it }}$. The marginal cost function of taxation is assumed not to vary over time. Government expenditure is assumed to followed an exogenously given time path. Therefore, if $\tau_{i t}$ is increased temporarily above its permanent level and later reduced by the same amount below its permanent level, a positive intertemporal net tax burden remains.

As shown in Barro (1979), minimization of the total cost of taxation over time, given the present value budget constraint, implies equality of $\tau_{i t}$ over time. As shown in Sahasakul for a single country, after substituting $E\left(\tau_{i t+j}\right)=\tau_{i t}$ for all $k \neq 0$ in Equation 2, Equation 3 can be defined as follows:

$$
\tau_{i t}=\rho_{i} b_{i t-1}+\bar{g}_{i t}
$$

where $\rho_{1} b_{i t}-1$ equals the real interest rate minus real output growth times the ratio of real debt outstanding to real output for country $i$ at the end of period $t-1 . \bar{g}_{i t}$ is the ratio of permanent government expenditures to output for country $i$ at time $t$ and is similar to an annuity value of current and future values of $g_{i t}$.

According to Equation 3, only the ratio of permanent government spending to output and the ratio of previously outstanding debt to output determine the tax rate at time $t$. For example, a temporary increase in $g_{i t}$ would be primarily financed by debt, since any increase in $g_{i t}$ would be less than the current increase in $g_{i t}$. The tax rate 
would rise by less than the current increase in $g_{i t}$ implying a 'smoothing' of tax rates over time. Thus, tax smoothing provides a theory of government debt: deficits arise when government spending is temporarily high or when output is temporarily low.

Only new information about the future path of government spending and output would change $\tau_{i t}$. Given all currently available information, today's tax rate is an unbiased predictor of future tax rates. The random walk condition can be described as follows:

$$
\begin{array}{r}
\tau_{i t}=\mu_{i}+\tau_{i t-1}+\varepsilon_{i t}, \quad \varepsilon_{i t} \sim\left(0, \sigma^{2}\right) \text { and } \\
E\left(\varepsilon_{i t} \varepsilon_{i t-k}\right)=0 \quad k \neq 0
\end{array}
$$

where $\mu_{i}$ is a country-specific constant term or 'drift,' and $\varepsilon_{i t}$ is a white noise error term that is independent and identically distributed across countries and time. Equation 4 implies that $\tau_{i t}$ is nonstationary with a unit root. In addition, under the null hypothesis, given $\tau_{i t-1}$, no other lagged information should be helpful to predict $\tau_{i t}$. Therefore, evidence of lagged information that can predict $\Delta \tau_{i t}=\tau_{i t}-\tau_{i t^{-1}}$ would reject tax smoothing.

\section{DATA}

Panel data on the average tax rate series $(1 / 2 i t)$ will be examined for the period $1955 \pm 1988.2$ The average tax rate for each of 19 countries is calculated as annual central government revenue divided by annual Gross Domestic Product (GDP). The countries examined are the USA, Canada, Australia, Japan, New Zealand, Austria, Belgium, Denmark, Finland, France, Germany, Greece, Ireland, Italy, the Netherlands, Norway, Sweden, Switzerland, and the UK. Data comes from various editions of the International Financial Statistics Yearbook published by the International Monetary Fund.3

Tests for significant lagged information employ four lagged values each of the tax rate, the ratio of government expenditures to output, the growth of real GDP and a measure of the national government's political cohesion or unity denoted as polit. An additional term representing polit $_{\text {since }} 1975$ is also examined and is denoted as poldit.4 As in Roubini and Sachs, pold it is used to test the null hypothesis that political cohesiveness of national governments gained importance in the budget making process after 1974. Annual data on government expenditure and real GDP is available since 1960 and comes from various 
editions of the International Financial Statistics Yearbook. The political cohesion measure is taken from Roubini and Sachs and is available for 14 countries over the period $1960 \pm 1985.5$ The measure is a number from zero to three, determined by factors such as whether a parliamentary government has a majority or a presidential government has diff erent political parties controlling the executive and legislative branches. A value of zero indicates the most cohesive government and a value of three the least cohesive. See the Data Appendix for additional discussion of the data.

\section{EMPIRICAL TESTS}

\section{Unit root tests}

Panel unit root tests are performed using data on central government tax rates. The random walk implication is examined by testing the null hypothesis of a unit root. A unit root in $\tau_{i t}$ implies a nonstationary tax rate series with permanent changes.

A known drawback to single equation unit root tests is their relatively low power to reject the unit root null hypothesis when the stationary alternative is true. As such, if the null hypothesis cannot be rejected then one is uncertain if the time series truly has a unit root or the sample size is insufficient to reject the null. Panel unit root tests have been proposed to increase power. Im, Pesaran and Shin (1997, IPS hereafter) propose one such panel unit root test that allows for heterogeneous parameter values in each country. IPS derive the asymptotic properties of their panel unit root test statistic. Contrary to single equation tests, the panel unit root test statistic converges to a standard normal distribution.

To perform the IPS panel unit root test, augmented Dickey and Fuller (ADF) tests are first estimated for each country as follows:

$$
\Delta \tau_{t}={ }_{\alpha}+{ }_{\gamma t}+\beta \tau_{t-1}+\sum_{k=1}^{m} \theta_{k} \Delta \tau_{t-k}+\varepsilon_{t}
$$

where $\tau_{t}$ is the federal tax rate in country $i, \alpha$ is a constant term, $\gamma t$ is a linear time trend, and $\beta$ is the parameter that tests the null of a unit root. $\Delta \tau_{t-k}$ corrects for serial correlations, $m$ is the maximum number of $\Delta \tau_{t-k}$ terms included in Equation 5, and $\theta_{k}$ is a parameter estimated for each $\Delta_{T-k} \cdot \varepsilon_{t}$ is a contemporaneous error term that is assumed to be independent and identically distributed with zero mean and finite variance. After estimating single equation 
unit root tests for each country as in Equation 5, the panel test 'IPS statistic' is calculated from the average $t$-statistic $(\bar{t})$ as follows:

IPS statistic $=N^{1 / 2}\left\{\bar{t}_{N T}-E\left(t_{T} \mid \beta_{i}=0\right)\right\} /\left\{\operatorname{Var}\left(t_{T} \mid \beta_{i}=0\right)\right\}^{1 / 2}$

where $N$ is the number of countries, $\bar{t}$ is the average $t$ statistic from the $N$ single equation estimates of $\beta$, and $E$ is the expectation operator. Values of $E\left(\left.t_{T}\right|_{\beta_{i}}=0\right)$ and $\operatorname{Var}\left(\left.t_{T}\right|_{\beta_{i}}=0\right)$ are provided in Table 2 of IPS for different values of $T$ and $k$, where $T$ is the number of years in the panel and $k$ is the number of augmented terms $\Delta \tau_{t-k}$ included in Equation 5. Note that country-specific fixed effects are included in the panel test as $\alpha$ is estimated separately for each country. Common time-specific effects are included in the panel test by demeaning the data prior to testing as follows: $\tau_{i t}-\bar{\tau}_{t}$.

The method of Perron (1989) is utilized to endogenously determine the 'optimal number' of augmented terms $\Delta \tau_{t}-k$ included in Equation 5. Starting with a maximum number of $k=8$ augmented terms, the $t$-statistic of the parameter $\theta_{8}$ is examined for significance at the $10 \%$ level in an asymptotic normal distribution (i.e. absolute value of $t=1$.645). If the $t$-statistic is not significant, the last lagged term $\Delta \tau_{t-8}$ is dropped from the regression. The procedure is repeated for $k=7$ and so on, until a significant $t$-statistic is found, at which point the procedure stops with all lags $k \leqslant m$ remaining in the regression. This 'general to specific' procedure to select the optimal number of lagged firstdifferenced terms has been shown to perform favorably in terms of size and power as compared to alternative procedures. ${ }^{6}$ Since heterogeneous numbers of firstdifferenced lagged terms are allowed in the single equation ADF tests, the values of $\left.E^{(} t_{T} \mid \beta_{i}=0\right)$ and $\operatorname{Var}\left(\left.t_{T}\right|_{\beta_{i}}=0\right)$ utilized in Equation 6 are estimated as a weighted average of the values in Table 2 of IPS. ${ }^{7}$

The hypotheses tested using the IPS panel unit root test can be summarized as follows:

Null Hypothesis : $\beta_{i}=0$ for all $\mathrm{i}$

Alternative Hypothesis : $\beta_{i}<0, i=1,2, \ldots, N_{1}$,

$$
\beta_{i}=0, \quad i=N_{1}+1, N_{1}+2, \ldots, N
$$

Therefore, under the null hypothesis of a unit root tax smoothing is supported in all countries, while under the 
alternative hypothesis tax smoothing is rejected in one or more countries. Single equation unit root test results are reported in Table 1. The single equation tests reject the unit root null hypothesis only in one country (Finland) at the $5 \%$ level of significance. To determine if inability to reject the unit root null in more than one country is due to low power, the panel unit root test is undertaken using all countries except Finland. The results are reported in Table 2.

The IPS panel test statistic of $; 0: 827$ cannot reject the unit root null at any of the usual significance levels. Overall, the findings in Table 1 and 2 support tax smoothing by national governments.

Table 1. Individual ADF unit root tests of national tax rates 1955 1988

\begin{tabular}{lll}
\hline Country & $t$-stat. & $k^{*}$ \\
\hline Australia & -3.00 & 4 \\
Austria & -2.36 & 0 \\
Belgium & -1.54 & 0 \\
Canada & -1.84 & 0 \\
Denmark & -2.44 & 8 \\
Finland & $-4.09^{*}$ & 5 \\
France & -2.78 & 0 \\
Germany & -2.01 & 0 \\
Greece & -3.29 & 0 \\
Ireland & -3.32 & 0 \\
Italy & -0.90 & 0 \\
Japan & -1.49 & 3 \\
Netherlands & -1.91 & 0 \\
New Zealand & -0.92 & 0 \\
Norway & -2.83 & 0 \\
Sweden & -1.96 & 0 \\
Switzerland & -2.91 & 4 \\
UK & -2.53 & 0 \\
USA & -3.27 & 0 \\
\hline
\end{tabular}

Dependent variable is the ratio of central government revenue divided by GDP. ADF unit root $t$-test statistic is estimated for each country. All ADF tests include an intercept and time trend. All data has been adjusted for possible common time fixed effects by demeaning prior to testing. $k^{*}=$ optimal number of lagged first differenced terms in the ADF test. ${ }^{* *}$ and ${ }^{*}$ denote rejection of the unit root null hypothesis at the $1 \%$ and $5 \%$ levels of significance, respectively. Critical values come from MacKinnon (1991). 
Table 2. IPS panel unit root test of national tax rates $1955-1988$

\begin{tabular}{ll} 
Sample size & Estimated IPS test statistic \\
\hline 18 countries & -0.827 \\
\hline
\end{tabular}

Dependent variable is the ratio of central government revenue divided by GDP. IPS test statistic is estimated as in Equation 6. Data has been adjusted for possible common time fixed effects by demeaning prior to testing. The null hypothesis is a unit root in all countries. Critical values are asymptotic standard normal and are $-2.326,-1.645$, and -1.282 at the $1 \%, 5 \%$, and $10 \%$ levels of significance, respectively.

\section{Regression tests of lagged information}

Tax smoothing suggests that changes in $\tau_{i t}$ will be unpredictable, implying that the first-differenced tax rate will be orthogonal to lagged information. It may also be the case that tax rates behave as an unpredictable random walk for reasons other than tax smoothing. For example, changes in government spending, output, and political factors could individually, or in combination, cause $\tau_{i t}$ to behave as a random walk. To further examine the null hypothesis of tax smoothing, and to look for evidence of an alternative hypothesis, the first differenced tax rate is regressed on lagged values of itself, the ratio of government spending to output, the rate of growth of real GDP, and political cohesion. Results of testing in panel data are shown in Table $3 .^{8}$

Results in Table 3 cannot reject the null hypothesis that tax rate changes are unpredictable. Only one lagged variable $\left(\Delta g_{i t-1}\right)$ is significant at the usual levels. Results are not sensitive to inclusion of political variables. When lagged measures of political cohesion are included, no variables are significant at the usual levels. ${ }^{9}$ This is the case whether political variables are included for the entire sample or only after 1974. Overall, the results in Table 3 cannot reject tax smoothing and are in agreement with the panel unit root test results in Table 2 . 


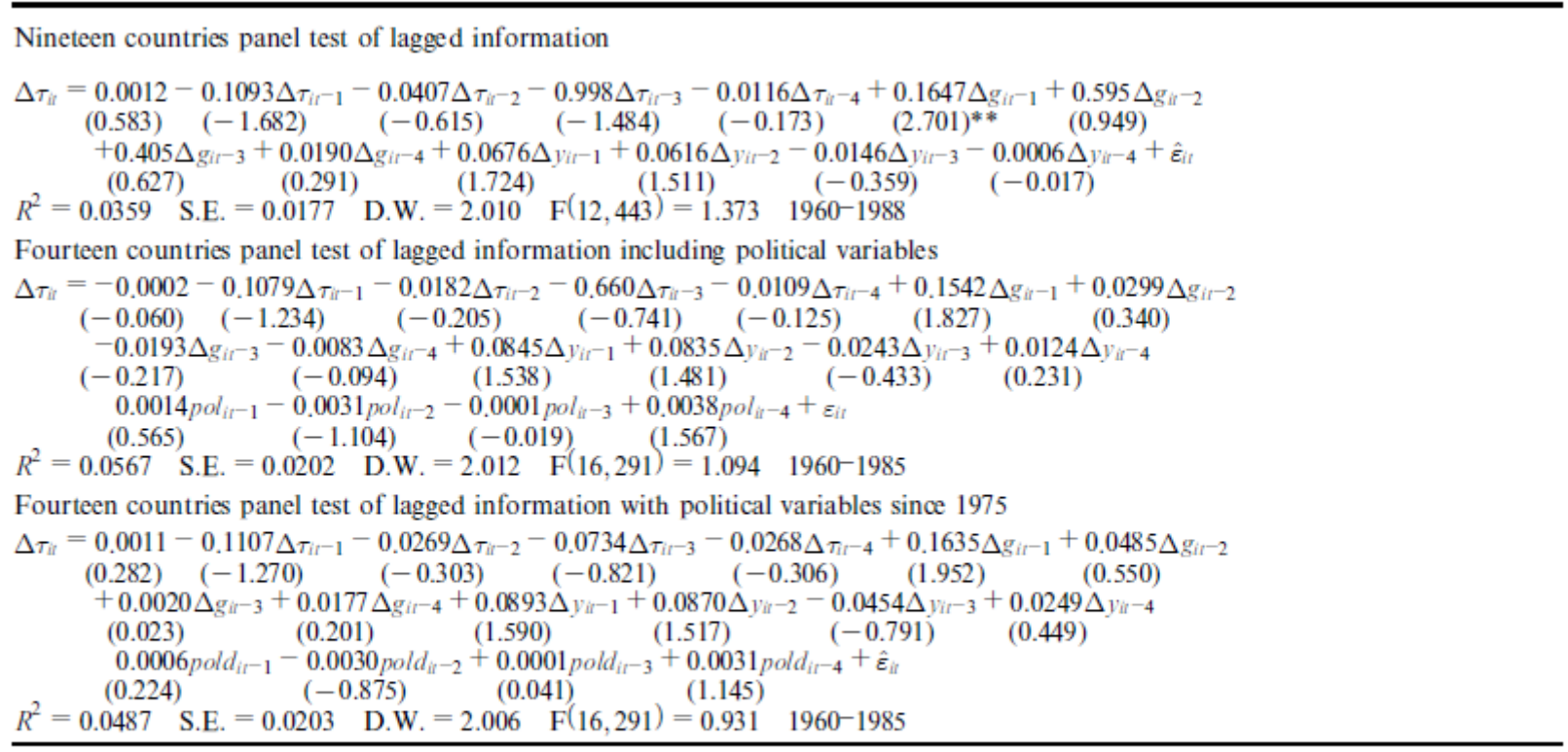

$\Delta \tau_{i l}, \Delta g_{i t}$, and $\Delta y_{i f}$ are the first differenced tax rate, government spending to output ratio, and growth of output for country $i$ in year $t$, respectively. $\Delta y_{i t}$ was calculated as $\ln y_{i t}-\ln y_{i t}-1 . p o l_{i t}$ is a measure of political cohesion in the national government of country $i$ in year t. pold ${ }_{i t}$ is the same as polit except only since $1975 . \hat{\varepsilon}_{i t}$ is the residual. $T$-statistics are shown in parentheses. *Significant at the $5 \%$ level. **Significant at the $1 \%$ level.

\section{VI . CONCLUSIONS}

National government tax rates were examined in 19 industrial countries for evidence of tax smoothing. If governments set tax rates to minimize distortions over time, the tax rate will be a nonstationary time series with a unit root and tax rate changes will be unpredictable. The null hypothesis was first examined by testing for a unit root in each country. The null of tax smoothing was rejected in only one country (i.e. Finland). To increase power, testing was undertaken in panel data utilizing time series from all countries except Finland. In spite of greater power, the panel test results could not reject the null hypothesis of a unit root in national tax rates. Panel regression tests were then undertaken to examine the null hypothesis that tax rate changes are unpredictable from past information and look for evidence of an alternative hypothesis. Results were unable to reject the null hypothesis that tax rate changes are unpredictable. Political variables were not significant in any case. Overall, the empirical findings presented in this paper provide support for tax smoothing as a theory of national government debt. 


\section{ACKNOWLEDGEMENTS}

The author thanks Levis Kochin and Paul Evans for helpful comments.

\section{REFERENCES}

Barro, R. J. (1979) On the determination of the public debt, Journal of Political Economy, 87, 940 \pm 71 .

Barro, R. J. (1981) On the predictability of tax-rate changes.

Unpublished manuscript, University of Rochester, Rochester, New York.

Barro, R. J. (1986) US deficits since World War I, Scandinavian Journal of Economics, 88, 195 \pm 222.

Benjamin, D. K. and Kochin, L. A. (1978) A theory of state and local government debt. Unpublished manuscript, Department of Economics, University of Washington, Seattle, Washington.

Benjamin, D. K. and Kochin, L. A. (1982) A proposition on windfalls and taxes when some but not all resources are mobile, Economic Inquiry, 20, 393 \pm 404 .

Bizer, D. S. and Durlauf, S. N. (1990) Testing the positive theory of government finance, Journal of Monetary Economics, 26, $123 \pm 41$.

Bizer, D. S. and Durlauf, S. N. (1991) Erratum, Journal of Monetary Economics, 27, 149.

Evans, P. and Karras, G. (1991) Are government activities productive?

Evidence from a panel of US states. Working paper, Department of Economics, The Ohio State University, Columbus, Ohio.

Gupta, K. (1992) Optimal taxation policy: Evidence from Canada, Public Finance, 47, 193 \pm 200.

de Haan, J. and Sturm, J. E. (1997) Political and economic determinants of OECD budget deficits and government expenditures:

A reinvestigation, European Journal of Political Economy, 13, 739 \pm 50 .

Huang, C. and Lin, K. (1993) Deficits, government expenditures, and tax smoothing in the United States: $1929 \pm 1988$, Journal of Monetary Economics, 31, 317 \pm 39 . 
Im, K., Pesaran, M. and Shin, Y. (1997) Testing for unit roots in heterogeneous panels. Working paper, University of Cambridge.

Kochin, L. A., Benjamin, D. K. and Meador, M. (1986) The observational equivalence of rational and irrational consumers if taxation is efficient, in West Coast Federal Reserve/ Academic Conference 1985, San Francisco: Federal Reserve Bank of San Francisco.

MacKinnon, J. G. (1991) Critical values for cointegration tests, in Long-run Economic Relationships: Readings in Cointegration, edited by R. F. Engle and C. W. J. Granger, Oxford University Press, Chapter 13.

$\mathrm{Ng}, \mathrm{S}$. and Perron, P. (1995) Unit root tests in ARMA models with data-dependent methods for the selection of the truncation lag, Journal of the American Statistical Association, 90, $269 \pm 81$.

Perron, P. (1989) The great crash, the oil price shock, and the unit root hypothesis, Econometrica, 57, 1361 \pm 401 .

Roubini, N. and Sachs, J. D. (1989) Political and economic determinants of budget deficits in the industrial democracies, European Economic Review, 33, 903 \pm 38 .

Sahasakul, C. (1986) The US evidence on optimal taxation over time, Journal of Monetary Economics, 18, $251 \pm 75$.

Strazicich, M. C. (1996) Are state and provincial governments tax smoothing? Evidence from panel data, Southern Economic Journal, 62, 979 \pm 88 .

Strazicich, M. C. (1997) Does tax smoothing dffer by the level of government? Time series evidence from Canada and the United States, Journal of Macroeconomics, 19, 305 \pm 26.

Trehan, B. and Walsh, C. (1988) Common trends, the government's budget constraint, and revenue smoothing, Journal of Economic Dynamics and Control, 12, 425 \pm 44 . 


\section{APPENDIX}

Revenue of the Central Government, Expenditures of the Central Government, Gross Domestic Product, and Real Gross Domestic Product: International Financial Statistics Yearbook, International Monetary Fund, Washington,

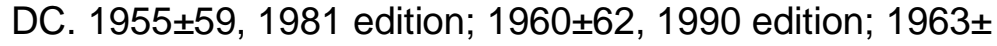
1988, 1993 edition. Political cohesion estimates come from Roubini and Sachs (1989).

In some countries, government revenues and expenditures are measured for the fiscal year (FY), while GDP is measured for the calendar year $(\mathrm{CY})$. Therefore, when revenues and expenditures for country $i$ are originally shown for the fiscal year they are converted into the calendar year as follows:

$$
C Y_{i t}=\lambda_{i} F Y_{i t}+\left(1-\lambda_{i}\right) F Y_{i t+1}
$$

where $0<\lambda<1$. New Zealand's GDP was also shown for the fiscal year and was, therefore, converted to the calendar year. Equation 1a is similar to (3.1) in Evans and Karras (1991). 